\title{
A video conferencing system could help address language barriers in the treatment of refugees
}

\author{
Georg Röggla
}

Received: 17 October 2012 / Accepted: 24 October 2012 / Published online: 20 November 2012

(C) Springer-Verlag Wien 2012

\section{Dear Editor,}

I read Carmen Pfortmueller's paper on acute health problems in African refugees with great interest [1]. As an amendment, I would like to point out to a major problem we face in treating these patients that is not mentioned in her paper. In my hospitals, we are encountering increasing numbers of patients with limited German or English proficiency, the only two languages spoken by the entire hospital team. For these patients, language and communication barriers pose a serious threat to receiving safe, high-quality health care. Due to these problems we are prone to errors in the diagnosis, costly and unnecessary use of diagnostic tests, patient dissatisfaction and readmission [2]. Professional interpreters shorten the length of a hospital stay [3]. We do not have professional interpreters at hand $24 \mathrm{~h}$ a day unfortunately, and therefore, have to manage with often suboptimal and unreliable help by family members or friends. I would greatly appreciate the implementation of a Video Remote Inter- preting system. Such systems have already been successfully used and could considerably improve the treatment of refugees [4].

\section{References}

1. Pfortmueller CA, Graf F, Tabarra M, Lindner G, Zimmermann H, Exadaktylos AK. Acute health problems in African refugees: ten years' experience in a Swiss emergency department. Wien Klin Wochenschr. 2012;124:647-52.

2. Karliner LS, Kim SE, Meltzer DO, Auerbach AD. Influence of language barriers on outcomes of hospital care for general medicine inpatients. J Hosp Med. 2010;5:276-82.

3. Lindholm M, Hargraves JL, Ferguson WJ, Reed G. Professional language interpretation and inpatient length of stay and readmission rates. J Gen Intern Med. 2012;27:1294-9.

4. Jones D, Gill P, Harrison R, Meakin R, Wallace P. An exploratory study of language interpretation services provided by videoconferencing. J Telemed Telecare. 2003;9:51-6. 